\title{
The Importance Of Business Research Skills In Entrepreneurial Orientation For Digital Transformation
}

\author{
Dr. Ileana Hamburg \\ Institut Arbeit und Technik, \\ Gelsenkirchen, Germany.
}

\begin{abstract}
In recent years area of entrepreneurship has gained significant attention nationally and internationally. It is one of the main skills priorities of national governments and EU council. Traditionally associated with commercial activity, entrepreneurship has gained traction as a key competence necessary to allow society as a whole to adapt to the changing economic climate. An important aspect particularly in the digital transformation is entrepreneurial orientation (EO) as the proactive nature of businesses of products and services in the market seeking for new innovations by even investing into it in spite of the high risk following it (Miller, 1993). It seems that organizations guided by a combination of market, technology, entrepreneurial learning (EL) and entrepreneurial orientation (EO) are well-positioned to take advantage of the opportunities presented by digital technologies. Small and medium sized companies (SMEs) greatly contribute to employment and wealth in Europe but there are limited studies into the specific skills needs required for SMEs into the future. Skills such as problem solving, critical thinking and entrepreneurship allow learners to adapt to changes, communication, digital skills and teamwork allow learners to collaborate and exploit technology in the changing workplace. Research is a key element of entrepreneurial success, but how these skills particularly workplace-oriented ones improve entrepreneurial orientation has not been widely explored in the literature. This paper explores the importance of EO and entrepreneurship today, the skills required to allow our society to become more entrepreneurial and identifies the potential of workplace research skills to develop entrepreneurial capacity in all facets of work, particularly within SMEs. The authors collaborated on many European projects aimed at improving work and education/training of entrepreneurs. The work presented int this paper resulted from surveys conducted within these projects regarding the problems SME staff have in connection with workplace transformation and entrepreneurship education and training. From this the paper proposes a conceptual model to facilitate the development of workplace research skills which will enhance EO in SMEs. Some developments within $n$ European projects to develop training for entrepreneurial learning in SMEs including EO are also given. The problems discussed in this chapter will also be used within the German initiative Mittelstand 4.0-Kompetenzzentrum with the participation of one author. Companies within this program are eager to improve their workplace research skills and change the EO and staff behavior in connection with digital workplaces.
\end{abstract}

Keywords: Entrepreneurship, Business Research Skills, Entrepreneurial Orientation, Entrepreneurial learning.

\section{INTRODUCTION}

Small and medium-sized enterprises SMEs are the dominant form of business organizations in the EU; more than $99 \%$ of enterprises in the European Union are SMEs. SMEs greatly contribute to employment and wealth in Europe: accounting for nearly $70 \%$ of European private service jobs. In Europe, the number of those employed by SMEs is high, particularly in sectors such as construction, metal products and the wood and furniture related industries. SMEs generate large portions of wealth in the EU (EC, 2013) 
Digital technologies have dramatically changed the organization and work in companies also in SMEs. This could be an opportunity or a challenge for SMEs if these organizations have a right strategy for digital transformation. It seems that organizations guided by a combination of market, technology, entrepreneurial learning (EL) and entrepreneurial orientation (EO) are well-positioned to take advantage of the opportunities presented by digital technologies. EO refers to the decision-making styles, practices, processes and behaviors that lead to 'entry' into new or established markets with new or existing goods or services (Lumpkin and Dess 1996; Wiklund and Shepherd 2003). Miller (1983) characterizes entrepreneurial orientation as the proactive nature of businesses of products and services in the market seeking for new innovations by even investing into it in spite of the high risk following it. A Digital Orientation in SMEs depends very often on individual characteristics of the owner manager in terms of IT knowledge, perceived benefits, and attitudes.

Referring the situation of SMEs, there is an EU average birth rate of $10 \%$ for small companies, however their growth rate remains quite low, at 2\% (Muller et al, 2017). Despite SMEs being more productive than larger organizations, they often remain stagnant (Eurostat, 2015). In many cases SME owner/managers are concerned about the survival of the firm and find it difficult to plan forward (Garland et al, 1984). Furthermore, in a recent project Archimedes, SMEs identified the burden of workload trying to sustain a business. They emphasized the need for staff/entrepreneurs to take initiative and seek new ideas. (O'Brien and Carroll, 2015). Drucker (1985) said that entrepreneurs are those that sense changes in the future and find ways to adapt to this change. Entrepreneurs who can use this change as a chance will affect the productivity of resources and earn entrepreneurial profits (Say, 1815). Cantillon (1755) said entrepreneurs are those that make the rational decision to make profits despite the risks that follow with it. To accomplish innovations, entrepreneurs need to tolerate high risks from starting a business because they are under fierce competition from existing

There are limited studies into the specific skills needs required for SMEs. In a recent study conducted by the EU Skills, panorama transversal skills were highlighted as becoming increasingly important. Skills such as problem solving, critical thinking and entrepreneurship allow learners to adapt to changes (EU, 2006). In addition, communication, digital skills and teamwork allow learners to collaborate and exploit technology in the changing workplace. Broad skills that allow SMEs to adapt to a wide variety of situations may be key. For example, skills that allow their employees to proactively look for business opportunities both internally and externally and identify how they can exploit these opportunities with their existing resources. This paper will explore the potential of workplace research skills to stimulate the employees' ability to systematically identify new opportunities and manage the implementation of these to improve the performance of the company.

Entrepreneurship is one of the key elements that will lead to a successful business performance under highly uncertain business conditions.

Research is often cited as a key element of entrepreneurial success, but the capacity of research skills to improve EO in a SME and so also the entrepreneurship capacity has not been in the literature.

Another problem is (Gibb and Hannon (2006), the way entrepreneurship is taught needs to be significantly changed. Students claimed that entrepreneurship courses not only provide students basic knowledge and skill for entrepreneurship but also make students have a positive attitude towards entrepreneurship. Entrepreneurship skills are important and entrepreneurship education should teach these skills such as the ability to create high 
performing culture, the ability to connect and network and the ability to lead and work in teams. It is difficult to teach EO but during the entrepreneurial learning students can learn some competences for development of EO. Students can study the factors that lead to failure in entrepreneurship and can avoid the same mistakes.

The paper identifies the skills that contribute to the modernized competence of entrepreneurship and explores why these are required for SMEs to grow. It examines the potential role of high level of EO and research skills in EO for grow in SMEs particularly for digital transformation. The paper then considers the training approaches, which can facilitate the development of a strategically EO and research skills. Finally, we present a case study of a project exploring the impact of workplace research skills on the development of EO in SMEs.

\section{ENTREPRENEURIAL SKILLS AND STRATEGICALLY EO FOR GROWTH ORIENTED SME BUSINESS}

Entrepreneurship is an area, which has long lacked consensus. However, in recent years it has become a key priority area. In 2015, the EU commissioned a study into the area resulting in a universal definition of entrepreneurship. The definition has modernized the view of entrepreneurship as a responsibility of society as a whole rather than the traditional businessperson.

' EntreComp defines entrepreneurship as a transversal competence, which applies to all spheres of life: from nurturing personal development, to actively participating in society, to (re)entering the job market as an employee or as a self-employed person, and also to starting up ventures (cultural, social or commercial). It builds upon a broad definition of entrepreneurship that hinges on the creation of cultural, social or economic value. It thus embraces different types of entrepreneurship, including intrapreneurship, social entrepreneurship, green entrepreneurship and digital entrepreneurship. It applies to individuals and groups (teams or organizations) and it refers to value creation in the private, public and third sectors and in any hybrid combination of the three. '(Bacigalupo et al, 2016).

Consequently there is a drive to incorporate entrepreneurship into all forms and levels of education so it is widely developed and disseminated, allowing all individuals to become active citizens. This modern view requires modern approaches to entrepreneurship education.

There are conflicting views of entrepreneurship ranging from leadership, innovation, risk taking and management as well as behaviorist and trait approaches (Emmanuel, 2010; Hamburg and O'Brien, 2014) To overcome ambiguity concerning the competence of entrepreneurship, the ENTRECOMP framework was developed by the EU commission in 2016 (Bacigalupo et al, 2016). It classifies entrepreneurship as having three competence categories and 15 different elements, which are interrelated. The three competencies are Ideas and opportunities', 'Resources' and 'Into Action'.

The 'Ideas and opportunities' category is concerned with identifying opportunities, developing initiatives to exploit these opportunities and determining the value that can be obtained from these. The 'Resources' category is concerned with planning and leveraging the personal, internal and external resources to develop initiatives to exploit such opportunities. 'Into action' is concerned with implementing initiatives, creating value from them and evaluating success. Many of these skills could be applied to the needs of stagnant SMEs wishing to grow. Skills such as financial literacy and digital skills are key for SMEs during the scale up phase (Muller et al, 2017). The ENTRECOMP addresses such skills gaps, for example, financial literacy and digital entrepreneurship are identified as a competency in the resources classification of the 
framework whereby the learner identifies the financial and technological resources required to exploit new business opportunities.

The framework also integrates some of the key competencies identified by the EU in the LLL policy, for example, 'taking the initiative' in 'ideas and opportunities' are concerned with solving longstanding problems.

In connection with digitalization, the DigComp 2.0 framework (https://ec.europa.eu/jrc/en/digcomp/digital-competence-framework) identifies the key components of digital competence necessary in entrepreneurship for digital transformation:

- Information and data literacy i.e. Articulating information needs, locating and retrieving digital data, information and content, judging the relevance of the source and its content, storing, managing, and organizing digital data, information and content.

- Communication and collaboration i.e. interacting, communicating and collaborating through digital technologies while being aware of cultural and generational diversity, participating in society through public and private digital services and participatory citizenship, managing one's digital identity and reputation.

- Digital content creation i.e. Creating and editing digital content, improving and integrating information and content into an existing body of knowledge while understanding how copyright and licenses are to be applied, knowing how to give understandable instructions for a computer system.

- Safety i.e. protecting devices, content, personal data and privacy in digital environments, protecting physical and psychological health, and being aware of digital technologies for social well-being and social inclusion and of the environmental impact of digital technologies and their use.

- Problem solving i.e. identifying needs and problems, resolving conceptual problems and problematic situations in digital environments, using digital tools to innovate processes and products, keeping up to date with the digital evolution.

EO has been conceptualized by Miller (1983) and Covin and Slevin (1989), and denotes the strategic orientation of firms firm towards innovativeness, proactiveness, and risk taking. Innovativeness refers to new and creative processes and the development of new ideas through experimentation (Lumpkin and Dess, 1996). Proactiveness means "seeking new opportunities which may or may not be related to the present line of operations, introduction of new products and brands ahead of the competition and strategically eliminating operations which are in the mature or declining stage of the life cycle" (Venkatraman, 1989, p. 947). Risktaking describes the uncertainty that follows when top-managers or firms behave entrepreneurially. Since its introduction. Other authors add "autonomy" and "competitive aggressiveness" (Alistair R Anderson, Sarah L Jack (2008) Role typologies for enterprising education: the professional artisan? Journal of Small Business and Enterprise Development. 15(2) 259-273).

EO is one of the most dominant research streams within entrepreneurship research (Covin and Lumpkin, 2011). Studies have been done in various cultural contexts (e.g., Antoncic and Hisrich, 2001; Hughes et al., 2007) and industries. In 2009, Rauch et al. (2009) did a metaanalysis of the EO - performance relationship and found a positive relationship between EO and business performance in different cultural contexts, countries, and industriesntrepreneurial skills have a substantial contribution to the development of a strategically EO. 
The next section explores how workplace research skills can help to improve E0 particularly to adapt to digital transformation.

\section{RESEARCH SKILLS AND THEIR IMPACT}

Research is required for innovation and innovation is needed to generate ideas for entrepreneurship. Traditionally entrepreneurship programmes are focused on venture creation.

But the development and execution of strategic plans towards digitalization is an organizationwide phenomenon and requires a new view of entrepreneurship and the cooperation of employees working at different levels (Floyd and Lane, 2000). Employees will be better able to execute a strategy when they understand the added value for the firm (Aaltonen and Ikävalko, 2002). A clear vision on the role of digitalization, that is communicated and shared throughout the organization, can aid the process of aligning interests and improve strategy execution (Wilson, 1992). Webster (1992) finds that strategy should be in line with the organization's orientation or culture, which encompasses the fundamental values and beliefs that guide the organization. Understanding of what the company stands for in terms of digitalization and how digitalization will aid goal attainment in the future provides guidance in the formulation of strategy itself, and sequentially, a justification for the strategic decisions made. This requires a "digital" EO and a corresponding entrepreneurship education including the achieving of research skills particularly oriented to digital aspects in workplace is necessary.

Research is a process of scientific inquiry, it is traditionally limited to academia however there is an increasing need for research to be applied to practical situations and societal needs (Plowright, 2016).

Research skills empower the employee to identify and gather the most appropriate material to their learning needs; as a result, it encourages a 'learning to learn approach'. The approach will allow employees to learn the skills to gather data in a systematic manner to fill knowledge gaps in their organization. These skills can be applied to a wide variety of contexts, disciplines and professions.

In the workplace, research skills are focused on the business tasks and the application of evidence based knowledge orientated towards practical outcomes. In addition to enhancing the company, the collaboration between academic and workplace learning provides individual skills by allowing the development of personal expertise in terms of proven high-level intellectual skills, skills of better judgement of success and ability to act as self-motivated learners.

However, pedagogical approaches to developing research skills are limited to doing so in an academic environment. Head, (2012) highlighted the importance of information skills in the workplace. In addition, there have been some studies into the development workplace information literacy in recent years (Head, 2012; Willison, 2012; Bird, 2016). However little research has been done on how to exploit workplace research skills to enhance entrepreneurial culture.

In an academic environment, a phased approach is preferred with tutors presenting increasingly complex scenarios for students to research, with the final stages extending student autonomy to choose their own research; this is usually the case for a final year student research project. (Symons et al 2017; Torres and Jansen, 2016) In addition, Inquiry Based 
Learning (IBL) approaches are favored due to the similarity between the phases of research and inquiry based teach (Davis et al, 2006)

Plowright, 2016 suggests a new model of research is needed that incorporates the rigor of traditional research but explores the application of research at a contextual level. He uses a FRaIM model that contextualizes research questions from professional, organizational, policy, national and theoretical contexts to ensure research is directed at relevant emerging needs.

The Research skill development (RSD) framework is a model that aims to formalize an approach for developing research skills in academia. It specifies six key phases which are conceptualizing/clarifying and posing questions/finding and generating data/evaluating/reflecting upon and critiquing research methods/source credibility and arguments/organizing and managing info/analyzing data/synthesizing data/communicating with awareness of ethical and social issues throughout the process. (Willson, 2012)

To allow us to exploit research skills as a method of developing entrepreneurial capacity in SMEs, we require a learning method which aligns to both the pedagogy of developing research skills and entrepreneurship education. Inquiry based learning is a methodology which is adopted in both contexts. For example, Kakouris, 2015, highlights the use of problem-based learning and the importance of reflection at both the individual level (metacognition) and organizational level (reflective practice) as being key in developing entrepreneurial skills. The next section will explore the conceptual learning methodology for our project in more detail.

As this paper is focused on the exploitation of research skills to develop a strategically EO, it aligns the phases of inquiry-based learning with the research phases. As a result, an adapted version of the inquiry-based learning model will be used as a conceptual framework.

An extensive comparative literature review into the phases of inquiry in I/EPBL was reported by various researchers. They categorized five phases of inquiry, these phases are detailed and all encompassing. It consists of five phases:

- Orientation - identifying an area of inquiry, this can include examining theories, conducting an initial inquiry through exploration or a needs assessment. This can be done by considering social, political, professional, organizational and cultural perspectives as in the FRAIM model.

- Conceptualization - based on the initial orientation, identifying questions or hypothesis

- Investigation - this involves planning the research, identifying resources, designing data collection methods and analyzing and interpreting data.

- Conclusion - this involves drawing conclusions from the data and identifying how they address the hypothesis or questions identified in phase 2.

- Discussion - this involves communicating results and reflecting on success and identifying future research opportunities'.

However, from a workplace research perspective, these stages appear linear and learners do not communicate or reflect on their progress, until last phase. Both elements are critical in a workplace environment. There is also no mention of ethical considerations, which are necessary when examining opportunities from an interorganizational perspective. The model is also focused on individual research but as we can see from the literature, collaboration is a necessary part of workplace research. In addition, it is based on traditional research approaches, but the current model does not account for action research and if a researcher wants to implement and evaluate a model or framework. The RSD phases of research cycle 
account for 'design/planning' as a separate stage and communicating throughout (Willson, 2012) it is suggested to add a phase dedicated to planning the research. In addition, some of the phases have been extended:

\section{A CONCEPTUAL MODEL FOR DEVELOPING RESEARCH SKILLS TO SUPPORT EO AND TRAINING}

In 2018 the authors started the Erasmus + project REINNOVATE, aimed to translate such policies within entrepreneurship into practice by focusing on cultivating an entrepreneurial culture in small companies supporting digitalization (Hamburg et al., 2018).

The training developed within the Reinnovate project combines entrepreneurial and learning orientations which will led to a more balanced approach to innovation. Moreover, the entrepreneurial orientation of learning may lead organizations down a costly and time consuming path of experimentation (Pelham, 2000), and may result in sub-optimal allocation of limited resources (Lonial \& Carter, 2015).

Prior to the starting the project, the REINNOVATE consortium conducted a survey to determine the challenges and needs of 142 SMEs in Europe in order to be innovative, to grow and to cope with digital changes. The survey focused on the barriers to innovation or other common problems SME have when trying to be innovative. The main challenges were concerning the availability of resources, lack of time, of internal skills, lack of ideas, organizational barriers, company culture, and staff behavior in connection with digital changes. It was found that $97 \%$ of asked companies want to become more innovative. The main barriers to innovation are resources (60\%) i.e. specialized equipment, staff.

About 38\% of SMEs answered that skills to use digital technologies to deliver new products and services or new digital business models are missing.

The survey explored the potential of SME collaboration of with Higher Education institutes in order to help them to be more innovative. The hypothesis was that leveraging from public research organizations would address the resourcing issues SMEs faced regarding innovation. One of the main concerns SMEs had was that higher education does not understand SMEs business needs or take too long to design and implement solution SMEs can use.

Research skills were seen as significantly important with, 87\% of SME identifying research skills as important or very important to their organization, however there is a significant skills gap with $62 \%$ of SMEs having no research skills.

To address such skills gaps the Reinnovate consortium with higher education institutes and research organizations, chamber of commerce and SME representative bodies will develop research skills to stimulate the employees' ability to systematically identify new opportunities and manage the implementation of these to improve the performance of the company. Simultaneously skills in problem solving, creativity, communication and critical thinking will be developed.

Phase 1 and 2: Orientation and Conceptualization- This involves systematically identifying ideas by actively seeking opportunities and questioning. The learner will conduct an initial inquiry through exploration or a needs assessment (exploring opportunities).

Phase 3: Planning - This involves actively planning in a systematic manner to determine how to exploit specific business opportunities, template and/or checklists can facilitate with this. 
Phase 4: Investigating - This involves actively investigating the business opportunity by systematically gathering data to allow them to test hypothesis and answer research questions.

Phase 5: Impact - Actively reflecting on the impact of the project from a social, cultural, professional, organizational and economic impact. Also reflecting on the impact of the project from a personal perspective in terms of what has been learned and determining how what was learned can be applied to other areas of the organization or business

At the practical realization of the learning program to support EO of entrepreneurs the project members had a look at the five elements that comprise EO and which of them can be learned not only during the training program but further in the organisation. An autonomous behavior can be developed over time taking into consideration that some people will have more desire for autonomy than others due in part to their personality, educational background and experience. Entrepreneurs should be encouraged to be more willing to make autonomous decisions and accept the responsibility that this involves.

Competitiveness can also be encouraged particularly by managers. To be innovative it is necessary to develop creativity and the ability to think in divergent ways. (I.e. Managers by using convergent thinking). This is suitable where the rules are known and the system is performing as it was designed to do. But in uncertain and turbulent environments like in digitalization design thinking is needed. Design thinking is a systematic, human-cantered approach to solving complex problems. Solutions and ideas are concretized and communicated in the form of prototypes as early as possible, so that potential users can test them and provide feedback - long before the completion or launch. In this way, Design thinking generates innovation and practical results.

And a change to the organization's culture, climate, reward and remuneration systems and also how it measures performance is necessary besides the learning.

Being proactive about opportunity recognition and taking prompt action to try to exploit such opportunities is treated in the literature. Managers should be more autonomous and to pursue opportunities that offer new innovative solutions to problems and the culture of the organization needs to be more open.

Risk taking is dependent on the organization's willingness to accept the potential for failure and to be tolerant when good ideas don't succeed. Managers are generally risk averse because the role of a "manager" is to maintain the system's status quo and ensure that it operates efficiently. Their primary duty in an organization is to reduce risk by reducing uncertainty via control systems more possible in an environment of certainty.

Four entrepreneurial learning modules have been developed and are offered next months in national languages to SME staff to help them:

- to use workplace-oriented research to identify opportunities from national \& international perspectives incorporating digital transformation.

- to gather and analyze the relevant data to allow them to implement a digital business opportunity or an innovative idea in connection with digital transformation.

- to manage an own research project about a digital business model and evaluate it.

The training process will be mostly by using digital media supported by face-to-face sessions and a mentoring process in partner countries Ireland, Germany, Lithuania, Romania and Spain. Design thinking is planned for the development of innovativeness. Groups of learners will be organized and a competition will be organized. Risks in each project will be evaluated. 


\section{CONCLUSIONS}

Entrepreneurial Orientation is often mentioned as an antecedent of growth, competitive advantage and superior performance, and it seems that research skills and the process of learning could influence this. To develop entrepreneurial research skills and a EO suitable to digital transformation, learning needs to be situated in a work environment. If students are professional working students this is relatively easily addressed. However, if students are full time a period of work placement or allocated industry projects will be required..

The proposed learning model allows learners to actively identify and pursue business opportunities in a systematic manner. It explores pedagogical approaches to implementing the ENTRECOMP framework. This pedagogical approach incorporates the inquiry-based leaning with workplace learning approaches to workplace research skills, assisting SMEs to grow. It is recommended that VET systems integrate this into work placement, community based education and industry project modules as a method of allowing students to apply their learning in a practical context and for professional learners to enable them to integrate formal and informal workplace learning

\section{References}

Bacigalupo, M., Kampylis, P., Punie, Y., \& Van den Brande, G. (2016). ENTRECOMP: The entrepreneurship competence framework. Luxembourg: Publication Office of the European Union.

Bird, N. (2016). Information Literacy for the Workplace: a review of the literature and research proposal. National Conference on Information Literacy. Zhenjiang, China.

Cantillon, R. (1755), "Essai sur la nature du commerce en general", Fetcher Gyler.

Cooney, T. M., \& Bygrave, W. D. (1997). The evolution of structure and strategy in fast-growth firms founded by entrepreneurial teams. In Working Paper presented at the Babson Entrepreneurship Conference.

Covin J, Slevin D (1989) Strategic management of small firms in hostile and benign environments. Strateg ManagJ $10(11): 7$.

Davis III, T. H., Wagner, G. S., Gleim, G., Andolsek, K. M., Arheden, H., Austin, R., ... \& Noga Jr, E. M. (2006). Problembased learning of research skills. Journal of Electrocardiology, 39(1), 120-128.

Emmanuel, C. L. (2002). Entrepreneurship: A conceptual approach. Lagos: Concept Publishing Ltd.

EU (2016). Skills Challenges in Europe 2016. Retrieved from http://skillspanorama.cedefop.europa.eu/sites/default/files/2016_Skills_Challenges_AH.pdf

European Commission (2008). Entrepreneurship in Higher Education, Especially Within NonBusiness Studies. Luxembourg: Office for Official Publications of the European Communities.

European Commission (2013). Communication from the commission to the European Parliament, the Council and Social Committee: EU Quality Framework for anticipation of change and restructuring.

European Commission (2015). Digital Entrepreneurship Monitor. Retrieved from https://ec.europa.eu/growth/tools-databases/dem/monitor/statistics\#/home

EUROSTAT (2015). Statistics on small and medium-sized enterprises Dependent and independent SMEs and large enterprises.

Field, S., Franklin, M., (2013). Micro-data Perspectives on the UK Productivity Conundrum. Office for National Statistics. Retrieved from

http://www.ons.gov.uk/ons/dcp171766_295470.pdf

Gibb, A., \& Hannon, P. (2006). Towards the entrepreneurial university. International Journal of Entrepreneurship Education, 4(1), 73-110.

Hamburg, I., O'Brien, E., Vladut, G.(2018). Workplace-oriented research and mentoring of entrepreneurs: cooperation university - industry. Archives of business research, no. 6, 243-25.

Hamburg, I., \& O'Brien, E. (2014). Using strategic learning for achieving growth in SMEs. Journal of information technology and application in education, 3(2), 77-83. 
Hamburg, I. (2015). Learning approaches for entrepreneurship education. Archives of Business Research, 3(1).

Head, A. J. (2012). Learning curve: How college graduates solve information problems once they join the workplace.

Hughes M, Morgan RE (2007) Deconstructing the relationship between entrepreneurial orientation and business performance at the embryonic stage of firm growth. Ind Mark Manag 36(5):651-661.

Kakouris, A. (2015). Entrepreneurship pedagogies in lifelong learning: emergence of criticality? Learning, Culture and Social Interaction, 6, 87-97.

Kim, S. J., \& Kwon, I. (2017). On a Focusing-Balancing Dilemma in SMEs. Academy of Management Proceedings; Vol. 2017, No. 1, p. 17630.

Kutzhanova, N., Lyons, T. S., \& Lichtenstein, G. A. (2009). Skill-based development of entrepreneurs and the role of personal and peer group coaching in enterprise development. Economic Development Quarterly, 23(3), 193-210.

Long, C. S., Ajagbe, M. A., \& Kowang, T. O. (2014). Addressing the issues on employees' turnover intention in the perspective of HRM practices in SME. Procedia-Social and Behavioral Sciences, 129, 99-104.

Lumpkin, G. T. and Dess, G.G. (1996), "Clarifying the entrepreneurial orientation construct and linking it to performance", Academy of Management Review, Vol. 21 No. 1, pp. 135-172.

Miller, D. (1983), "The correlatives of entrepreneurship in three types of firms", Management Science, vol. 29 No. 7, pp. 770-791.

Morgan-Thomas, A. (2016). Rethinking technology in the SME context: Affordances, practices and ICTs. International Small Business Journal, 34(8), 1122-1136.

Muller, P., Julius, J., Herr, D., Koch, L., Peycheva, V., \& McKiernan, S. (2017). SME Performance Review 2016/2017: Annual Report on European SMEs 2016/2017. Focus on self-employment. European Commission, DirectorateGeneral for Internal Market, Industry, Entrepreneurship and SMEs.

O'Brien, E., Carroll, L. (2015). A report on how problem based learning and ICT can support SMEs in Europe. Retrieved from http://www.archimedes2014.eu/doc/reports/European\%20report\%20on\%20SMEs.pdf

Plowright, D. (2016). Developing Doctoral Research Skills for Workplace Inquiry. In Fourie-Malherbe, M., Aitchison, C., Blitzer E, Albertyn, R. (Eds). Postgraduate Supervision-Future Foci for the knowledge society (pp. 241- 254). Stellenbocsh: SUN PRESS.

Rauch, A. , Wiklund, J., Lumpkin, G.T., \& Frese, M. (2009). Entrepreneurial orientation and business performance: An assessment of past research and suggestions for the future. Entrepreneurship Theory and Practice, 33(3), 761787.

Sheehan, M. (2014). Human resource management and performance: Evidence from small and medium-sized firms. International Small Business Journal, 32(5), 545-570.

Symons, S. L., Colgoni, A., \& Harvey, C. T. (2017). Student Perceptions of Staged Transfer to Independent Research Skills During a Four-year Honours Science Undergraduate Program. Canadian Journal for the Scholarship of Teaching and Learning, 8(1), 6.

Torres, L., \& Jansen, S. (2016). Working from the Same Page: Collaboratively Developing Students' Research Skills Across the University. Council on Undergraduate Research Quarterly, 37(1).

Willison, J. W. (2012). When academics integrate research skill development in the curriculum. Higher Education Research \& Development, 31(6), 905-919. 